\title{
Whole Process Engineering Consulting
}

\section{Shumin Li}

\author{
School of Management, Tianjin University of Technology, Tianjin, China. \\ 1375861492@qq.com
}

\begin{abstract}
The whole process engineering consulting is to carry out project management with planning as the guide, investment management and control as the main line and value-added as the goal. Traditional construction mode is to design, construction and supervision of construction projects, such as phase separated, each unit is responsible for different stages and different professional work, this not only increases the cost, and the division of the construction project internal relations, in the process because of a lack of whole industry chain of the overall control, the flow of information is cut off, it is easy to cause all sorts of problems in the process of construction project management, and bring the hidden danger of safety and quality makes it hard for the owner to get the complete building products and services.
\end{abstract}

Keywords: Engineering planning, Value Engineering, Project value added.

\section{Introduction}

The implementation of whole-process engineering consulting, with highly integrated service contents, not only saves the investment cost, but also helps to shorten the project duration, improve the service quality and project quality, and effectively avoid risks, which is the embodiment of policy guidance and industrial progress.

\section{Planning Pilot}

\subsection{Engineering Planning}

The engineering planning here is an engineering plan that optimizes the function and technical route to meet the needs of the owner. In the project planning, it is necessary to do the planning work in the early stage of the project, carry out the preliminary basic data investigation, and plan according to the function of the overall planning of the project, the construction scale, project composition and construction cost.

\subsection{Investment and Financing Model Planning}

The investment and financing model planning here is the investment and financing model planning with the lowest life cycle cost and the maximum asset value. On the basis of value engineering analysis, the whole life cycle cost data is used to extend the focus to the project operation and demolition stage, and move forward to the feasibility study stage to select the optimal investment and financing mode. Full life cycle cost management must be coordinated with value engineering and cannot be separated.

\subsection{Design Optimization Based on Value Engineering}

Design optimization based on value engineering should follow two paths:

The preferred solution is to find the most cost-effective solution. The alternative construction can refer to the design specification and construction specification, match the cost indicator for a feasible solution, and select the solution with the smallest cost indicator;

The optimization plan is to calculate the value index of each system within the optimal single plan that has been selected. If the value coefficient is greater than 1, the design limit is increased. If less than 1, the design limit should be reduced. These are the basic applications of value engineering, we should not forget the initial heart! 
Construction technology and construction organization optimization based on constructability analysis

Design optimization based on constructability pursues construction convenience to reduce construction measures, followed by easy control of construction period, third is conducive to reducing death and injury accidents, and fourth is convenient for construction quality control. The specific performance is four reductions: lowering the requirements on the construction site, reducing the requirements on the skills of workers, reducing the dependence on construction machinery, and reducing the requirements for special construction schemes in the winter rainy season. It is also necessary to conduct an adaptive analysis of the construction schemes that match the feasible design schemes, and enumerate the indicators to score the highest scores after the scores.

Operation and maintenance plan optimization

The operation and maintenance plan optimization here is based on operational and maintenance analysis, revenue management and facility management. The program pursues the best operational performance, including cost/benefit analysis of operational projects, analysis of market acceptance of operating prices, risk assessment of environmental protection projects, and user-friendliness analysis (transfer convenient, disabled use, and action routes) The shortest), the convenience and economy of maintenance, the risk assessment of future market demand, and the analysis of public safety risk.

\section{Investment Management and Control}

Project management with investment management and control as the core is a new trend in the development of project management and engineering cost in China. Since the realization process of the three basic objectives of project management is a dialectical and unified process, the control of investment (cost) in practice can best reflect the balance between "cost, quality and duration" and is also the most efficient. Coordinate and manage these three objectives.

\subsection{Three Core Ideas of Investment Management}

(1) Correction is the main theme of investment control

(2) Internal control of error correction and prevention is the basic method of investment management and control

(3) The focus of investment control is in the early stage

\subsection{Investment Control Under Different Project Management Modes}

The evolution of the construction project management model has formed a variety of specific models. In the actual operation of the project, different project management models need to match different investment management methods and ideas. The following is an analysis of investment management and control in the three project management modes of DBB, EPC and PPP.

(1) DBB mode - strict control of engineering changes

Engineering changes are the main cause of DBB mode investment out of control. If the owner's needs change, the design is wrong, the construction is difficult or unfavorable, the contractor rationalizes the proposal. In the face of these changes, LCC, value engineering, constructability, BIM technology, etc. can be used for control.

(2) EPC mode - trust or not

The triangle mode zero-sum game color is too strong, and both sides of the contract are confronted. So there was an EPC design procurement and integration model, using the FIDIC silver book. The basis of EPC is cooperation. The premise of cooperation is trust, and the trust is manifested in the fact that the two parties do not exploit each other's vulnerabilities. China's implementation of EPC lacks the basis of trust, so the use of EPC integration, strict control, called the Chinese EPC.

(3) PPP mode - control project assets blur

PPP projects have been rushed to launch, and the previous projects have not been rigorous and inadequate. The various controls on the financial side were gradually improved, but the management 
and control at the project end was seriously absent. Therefore, it is more necessary to consult the whole process engineering.

The investment control of the PPP project is mainly to control the project assets falsification, and the PPP project is based on the nature of the government investment project, and the methods of reviewing, paying, supervising and clearing can be used for financial evaluation, auditing, and whole process engineering consulting. Tripartite supervision).

\section{Project Value Added as the Goal}

Adding value to the project is the task that is the easiest to unify thinking in the whole process of engineering consulting.

\subsection{Three Concepts of Project Value-Added}

(1) Value chain analysis

Value chain analysis is the analytical method proposed by Michael Porter in his theory of competitive strategy. Through the basic activities such as feasibility study, survey design and owner control, government supervision, bidding and contract, supervision and other auxiliary activities to conduct research, analyze the formation of the construction industry value chain.

(2) Value management

The basic model of value management is $\mathrm{V}=\mathrm{F} / \mathrm{C}$, which is proportional to the value and function, and inversely proportional to the full life cycle cost. We don't change the design, we only offer the best cost-effective solution.

(3). LCC

The full life cycle cost is the cost of construction and use that occurs during the effective use of the product.

\subsection{Three Major Means of Project Value-Added}

(1) Kelly curve

PPP+BIM realizes the forward integration of engineering cost consulting business and extends backwards; it solves the problem of resource mismatch. In the decision-making and preliminary design stage, the possibility of affecting project investment is $75 \%-95 \% ; 35 \%-75 \%$ in the technical design stage; $10 \%-35 \%$ in the construction drawing design stage; and in the construction stage, passing the technology Economic measures save investment is only 5\%-10\%

It can be seen that the early stage of decision-making and design is the most important stage affecting the project cost, and it is the most likely stage of saving. Utilize BIM as a tool to realize system analysis and transmission of existing past project data, so as to realize the feasibility of saving project investment.

(2) Constructability analysis

Constructability research is regarded as one of the most promising new construction management technologies in construction management technology, which can reduce project cost and improve project construction productivity. The designability of constructability is optimized to reduce construction cost, secondly to facilitate the control of construction period, the third is to reduce the risk of death and injury, and the fourth is to facilitate construction quality control. The specific performance is four reductions: lowering the requirements on the construction site, reducing the requirements on the skills of workers, reducing the dependence on construction machinery, and reducing the requirements for special construction schemes in the winter rainy season. It is also necessary to conduct an adaptive analysis of the construction schemes that match the feasible design schemes, and enumerate the indicators to score the highest scores after the scores.

(3) Operational analysis

According to the LCC idea, the cost of the operation phase accounts for up to $75 \%$ of the total life cost, so the design and construction should be fully considered for operationality. Operationality: including cost/benefit analysis of operational projects, analysis of market acceptance of operating 
prices, risk assessment of environmental protection projects, and user-friendliness analysis (convenient transfer, disabled use, and shortest action route), The convenience and economy of maintenance, future market demand risk assessment, and public safety risk analysis take the elements. Operational analysis is also done in the design phase and is an important part of design optimization. It must not be carried out until the operational phase.

\section{Conclusion}

The whole process engineering consultation is to carry out project management with planning as the guide, investment management and control as the main line, and project value-added as the goal. The planning pilot, the investment control will be implemented throughout the whole process to the actual project, to provide the owner with the best cost-effective solution, to achieve the effect of project value-added, will make the whole process of engineering consulting roads go further and further!

\section{References}

[1]. Tang T. Research on the Risk Identification for the International Engineering Contracting EPC Projects $[\mathrm{M}] / /$ Proceedings of the 21st International Conference on Industrial Engineering and Engineering Management 2014. Atlantis Press, 2015:477-482.

[2]. Xue-liang HOU. Instant Identification and Judgement on Engineering Project System States under Different Norm Value[A]. Science and Engineering Research Center. Proceedings of 2017 2nd International Conference on Mechatronics, Control and Automation Engineering (MCAE2017) [C]. Science and Engineering Research Centre: 2017:7.

[3]. Bopping Chen. A Study on Comprehensive Analysis and Control of Cost and Progress of Architectural Decoration Engineering from the Angle of Earned Value[A]. Singapore Management University. Proceedings of 1st International Conference on Education, Economics and Management Research (ICEEMR 2017) (Advances in Social Science, Education and Humanities Research Volume95) [C].Singapore Management University: 2017:4.

[4]. Hoaxing Wang. Product Design Innovation Based on the Theory of Value Engineering[A]. Proceedings of the 2017 International Conference on Culture, Education and Financial Development of Modern Society (ICCESE 2017) [C]. 